\title{
EDITORIAL
}

\section{STRESSORS FOR PARENTS OF CHILDREN WITH COCHLEAR IMPLANT IN PAKISTAN}

Faseeha Shafqat,

Editor TRJ, Speech and Language Rehabilitation Consultant Speech Language Pathologist, Bilquis Memorial Hospital, Islamabad Pakistan Email: faseeha.shafkat@gmail.com

Cochlear implants $(\mathrm{Cl})$ are electronic devices that are surgically implanted in children with profound hearing loss to enable them experience sensation of sound. U.S was the first to approve $\mathrm{Cl}$ surgeries for children in 1990 and the minimum age was lowered to 12 months by U.S Food and Drug Administration by 2002. ${ }^{1}$ Growing numbers of evidence has demonstrated positive outcomes of $\mathrm{Cl}$ in language and communication by improving children's speech perception and speech production. ${ }^{2}$ Outcomes of $\mathrm{Cl}$ are neither instant nor irrefutably assured and demands continuous effortful habilitation process to prove this surgery a wise decision. ${ }^{3,4}$ Evidence shows great variability in outcomes following $\mathrm{Cl}$ which indicates that children may continue to show hearing and communication problems. ${ }^{5}$ Long-term habilitation processes of $\mathrm{Cl}$ and continued exposure to difficulties generate many stressors to parents along with challenges to parental role. Furthermore, to ensure success of $\mathrm{Cl}$, parents play a key role by complying with whole rehabilitation process. Therefore any factor that can cause stress for parents and destroys their mental health, can affect child's progress. Literature reveals that psychological distress is more experienced among parents of children with $\mathrm{Cl}$ not only in comparison to parents of normal hearing children ${ }^{6}$ but also do parents of deaf and conventional hearing aid users. ${ }^{7}$

In Pakistan $\mathrm{Cl}$ programme began in 2000 and at that time due to financial constraints only few patients were able to afford this and faced many difficulties in its long term rehabilitation process. ${ }^{8}$ Currently many hospitals in liaison with international companies are offering $\mathrm{Cl}$ surgeries with habilitation services. Some of those hospitals are Dow University of Health Sciences Karachi, Capital Development hospital Islamabad, Combined Military Hospital Rawalpindi, Bahria International Hospital Lahore and Central park hospital Lahore. Many schemes also provide free cochlear implant surgery services with one year fund for habilitation services i.e. audiological services and speech therapies. It is commendable that services to patients of $\mathrm{Cl}$ in Pakistan are growing at exponential rate from selection of $\mathrm{Cl}$ candidate to habilitation process post-surgery, but parallel to that parents' increasing stress level affecting their psychosocial life cannot be ignored.

It has been observed that at first hand $\mathrm{Cl}$ poses great financial burden that can continue to upheaval at any stage of life even after bearing expense of costly $\mathrm{Cl}$ surgery, when any piece of device gets damaged or need repair. Even if insurance is sought it requires depositing minimum eighty thousand rupees per year that is only affordable for high economic strata. Services of $\mathrm{Cl}$ surgeries are only offered in few big cities and for every mapping and follow up. Patients from far-flung areas are required to travel long distances and for life long they become dependent on their $\mathrm{Cl}$ panel and/or company no matter how many difficulties, bad attitude and unprofessional habilitation services they witness and face. Parents victimhood shout out that many public and private sector institutes claim that they provide Auditory Verbal Therapy (AVT) but in actual these institutes are filled with trainees who themselves do not know the exact approach and trains child on total communication approach that make child dependent on gestures, lip reading and loud voice from messenger that overall affects typical milestones of listening development. Such truths get exposed when child was assessed by some expert speech therapist. Parents also reported that at times remarks of audiologist get stressful when within few months of implant they compare their child with some other child and states that the other one has got much verbal as compared to your child or why he/she hasn't started speaking yet. In opinion of parents who have gone through this long journey, many audiologists except few don't seem to be aware of typical listening milestones.

Many parents reported that speech therapy is a long-term process which itself carries financial load but even it is taken, you can never be assured that therapist is following standardized steps or not. Some parents reported that we immediately got happy when our child started uttering many word within few therapy sessions soon after 
device switched on but after long time they got to know that these words are not in child's listening but only taught with lip-reading for immediate results. When conflict arises in opinions and practices of professionals serving $\mathrm{Cl}$ patients, then conflict among parents of $\mathrm{Cl}$ children also arise when each parent gets believer of different professional opinion. This difference of opinion consequently leads to stress in their marital and family life.

Increased stress level among parents of cochlear implanted children is an indication of serious threat to the mental and emotional health of a family system rearing such child. Studies should be conducted to figure out all possible factors rooting this stress. Though, it is not possible for multidisciplinary team (MDT) of Cl to lower the stress that arises secondary to expense of $\mathrm{Cl}$ but stressors that up thrust due by malpractice and inappropriate guidance of members in MDT should be eradicated by ensuring provision of trained professionals.

\section{REFERENCES}

1. Spencer P, Marschark M. Cochlear implants: Issues and implications. In M. Marschark (Ed.), Oxford handbook of deaf studies, language, and education. New York: Oxford University Press. 2003;434-448.

2. McRackan TR, Bauschard M, Hatch JL, Franko-Tobin E, Droghini HR, Nguyen SA, et al. Meta-analysis of quality-of-life improvement after cochlear implantation and associations with speech recognition abilities. Laryngoscope. 2018;128(4):982-90.

3. Geers AE. Speech, language, and reading skills after early cochlear implantation. Arch Otolaryngol Head Neck Surg. 2004;130(5):634-8.

4. Christiansen JB, Leigh I. Cochlear implants in children: Ethics and choices. Gallaudet University Press; 2002.

5. Bat-Chava Y, Martin D, Kosciw J. Longitudinal improvements in communication and socialization of deaf children with cochlear implants and hearing aids: Evidence from parental reports. J Child Psychol Psychiatry. 2005;46(12):1287-96.

6. Zaidman-Zait A. Everyday problems and stress faced by parents of children with cochlear implants. Rehabili. Psychol. 2008;53(2):139.

7. Burger T, Spahn C, Richter B, Eissele S, Lo"hle E, Bengel J. Parental distress: The initial phase of hearing aid and cochlear implant fitting. Am Ann Deaf. 2005;150(1):5-10.

8. Khan MI, Mukhtar N, Saeed SR, Ramsden RT. The Pakistan (Lahore) cochlear implant programme: issues relating to implantation in a developing country. J Laryngol Otol. 2007;121(8):745-50. 